\title{
Acute myocarditis associated with secondary cerebral edema in a patient with COVID-19: Case report
}

Isabella Cristina Mendes Rossa ( $\sim$ isabella.rossa@pucpr.edu.br)

PUCPR https://orcid.org/0000-0002-5885-7854

Gustavo Lenci Marques

PUCPR https://orcid.org/0000-0002-6057-0350

Carlos Alexandre Twardowschy

PUCPR https://orcid.org/0000-0003-3667-0412

\section{Case Report}

Keywords: COVID-19, SARS-CoV-2, cytokines, myocardial injury, myocarditis, cerebral edema

Posted Date: March 29th, 2021

DOl: https://doi.org/10.21203/rs.3.rs-318417/v3

License: (1) (i) This work is licensed under a Creative Commons Attribution 4.0 International License.

Read Full License 


\section{Abstract}

Female patient, 44 years old, admitted with symptoms of COVID-19. She presented elevation of cardiac troponin I, as well as diffuse hypokinesia in transthoracic echocardiography, which suggested the diagnosis of myocarditis. Next, a skull tomography showed diffuse cerebral edema and tonsilar herniation, and the patient evolved with brain death

\section{Introduction}

In December 2019, a series of pneumonia cases of unknown etiology emerged in Wuhan, China. ${ }^{(1)}$ Researchers identified severe acute respiratory syndrome coronavirus 2 (SARS-CoV-2) as being responsible for the infection, which was named COVID-19. Like other coronaviruses, SARS-CoV-2 uses the Angiotensin-Converting Enzyme II (ACE2) receptor for ligand binding before entering the cell. ${ }^{(2)}$ The ACE2 receptor is a membrane protein present in cardiomyocytes, type 2 pneumocytes, astrocytes, and other cells. $^{(3)}$

In addition to causing damage to the respiratory system, SARS-CoV-2 can trigger cardiac and brain injury. (4) In some cases of myocardial injury, SARS-CoV-2 particles have been identified in the myocardium, reinforcing the hypothesis that cardiotoxicity occurs. ${ }^{(5)}$ Likewise, studies suggest that the virus can infect the brain directly, reaching its parenchyma through the bloodstream and the olfactory system. ${ }^{(6)}$

Recent studies indicate that a considerable number of patients diagnosed with COVID-19 have myocardial injury, and that this condition is related to higher mortality rates and more severe disease outcomes. ${ }^{(5)}$ Cases of myocarditis are rare in patients with COVID-19, but when they occur in a fulminating way, they are associated with fatal outcomes to these patients. ${ }^{(6)}$ Therefore, further studies of cases of myocarditis in patients infected with SARS-CoV-2 are warranted.

\section{Case Report}

A 44-year-old female sought medical attention, with a condition of dry cough, dyspnea on moderate effort, odynophagia and myalgia. At the time of admission, the patient had a body temperature of $37.1^{\circ} \mathrm{C}$, blood pressure of $128 / 79 \mathrm{mmHg}$, heart rate of $94 \mathrm{bpm}$, and oxygen saturation $\left(\mathrm{O}_{2}\right)$ of $96 \%$. She had a history of dyslipidemia, for which she was taking statins, and was also overweight (body mass index: $27.68 \mathrm{~kg} / \mathrm{cm}^{2}$ ). The patient had been diagnosed with COVID-19 four days earlier through the reversetranscriptase polymerase chain reaction (RT-PCR) test. On the first day of hospitalization, a CT scan of the chest showed acute inflammatory pulmonary changes affecting about $50 \%$ of the lung parenchyma. Laboratory tests showed a cardiac troponin I level of $4.8 \mathrm{pg} / \mathrm{mL}$ (reference value: less than $11.6 \mathrm{pg} / \mathrm{mL}$ ), Creactive protein of $71.5 \mathrm{mg} / \mathrm{L}$ (reference value: less than $5 \mathrm{mg} / \mathrm{L}$ ), and normal blood cell counts. On day 2 , the patient evolved to Acute Respiratory Failure, and an orotracheal intubation procedure was performed. Then, a transthoracic echocardiogram found a left ventricular ejection fraction of $44 \%$, a diffuse hypokinesis and increased left ventricular dimensions, suggestive of myocarditis. On day 6 , the patient 
was improving, with an 02 saturation of 93\%, mild acidosis, and permissive hypercapnia on arterial blood gas. She evolved to hemodynamic instability due to circulatory shock, and the dose of vasoactive drugs was increased. She also presented fixed mydriatic pupils and absence of corneal eyelid reflex. On the same day, the cardiac troponin I level found was $11,576.6 \mathrm{pg} / \mathrm{mL}$ (reference value: less than $11.6 \mathrm{pg} / \mathrm{mL}$ ), which was the highest since day 1 (Fig. 1). The patient underwent a CT scan of the skull, which showed reduced differentiation between the white and the gray matter in the cerebral hemispheres, associated with expansive effect and tonsillar herniation; this picture being suggestive of cerebral edema. The electrocardiogram showed sinus tachycardia and no signs of myocardial ischemia (Fig. 2). The patient was under suspicion of brain death, so sedation was turned off, and hemodynamic, respiratory and cardiologic surveillances were maintained. On the seventh day, the patient died

\section{Discussion}

In addition to pulmonary involvement, the SARS-CoV-2 infection can impair myocardial function, triggering cases of acute myocarditis. Viral infections are common causes of this condition, which leads to focal or global myocardial inflammation, necrosis, and, in some cases, ventricular dysfunction. ${ }^{(7)}$ The symptoms of myocarditis usually present as chest pain, palpitations, fatigue and syncope. Increased markers of myocardial necrosis, nonspecific ST segment and T wave changes on the electrocardiogram, global hypokinesia and pericardial effusion on the echocardiogram, as well as histological changes in the biopsy, are all used as criteria for the diagnosis of myocarditis. ${ }^{(8)}$ The pathogenesis of this involvement might be associated with the infectious process triggered by SARS-CoV-2, which causes an excessive inflammatory response known as "cytokine storm".(9) This hyperinflammatory state appears in the advanced stages of critical cases of COVID-19, causing damage to multiple organs.(10) Additionally, during pulmonary infection, fever and tachycardia increase oxygen demand by the cardiac tissue. However, gas exchange impaired by continuous blood flow to lung regions of low ventilation causes a ventilation-perfusion mismatch, resulting in blood hypoxemia and, consequently, in worsening of oxygenation of the cardiac tissue.(11)

Yokoo et al. ${ }^{(4)}$ described the case of a patient diagnosed with COVID-19, who was over 80 years old and had a history of hypertension and ischemic stroke. Laboratory tests showed high levels of troponin T, electrocardiogram showed no signs of ischemia, and echocardiogram showed an ejection fraction of $35 \%$. This patient underwent a Cardiovascular Magnetic Resonance that revealed areas of delayed enhancement with ischemia in the left ventricular base septal wall, as well as diffuse hypokinesia and impaired global systolic function. Furthermore, cases of myocarditis associated with COVID-19 have also been reported in young people(12) and individuals with no cardiovascular risk.(13)

Patients with cardiac injury related to SARS-CoV-2 infection have an acute manifestation of COVID-19 with greater severity, characterized by elevated levels of C-reactive protein and more intense pulmonary involvement,(13) similar to the patient in the case study. The mortality rate is also influenced by the myocardial injury associated with COVID-19, being higher than $50 \%$ among patients with cardiac injury compared to $5 \%$ among those without it(14) 
In the present case report, in addition to myocarditis, the patient presented diffuse cerebral edema. Several mechanisms are proposed for the neurological complications caused by COVID-19. The first hypothesis is based on the hematogenous or axonal retrograde pathway with viral accumulation in endothelial and neuronal cells. Brain damage may also be related to pneumonia caused by SARS-CoV-2, seeing that when the virus passes through the lung parenchyma, it triggers an exaggerated accumulation of neutrophils, increased vascular permeability and the formation of exudates, leading to hypoxemia. In the brain, hypoxia promotes increased anaerobic metabolism, causing vasodilation and cerebral edema. (15) In this regard, the cerebral involvement of the patient in this case probably occurred due to severe hypoxia, which was also related to the occurrence of circulatory shock.

\section{Conclusion}

In addition to causing respiratory complications, SARS-CoV-2 infection can impair cardiac and cerebral function. Acute myocarditis, a manifestation of myocardial injury, is associated with more severe outcomes of COVID-19 and may lead to poor cerebral perfusion culminating in edema and brain death.

\section{Declarations}

\section{Ethics statement:}

The study "Acute myocarditis associated with secondary cerebral edema in a patient with COVID-19" was approved by the ethics committee of Pontifical Catholic University of Paraná, with approval number 30188020.7.1001.0020. The patient's next of kin provided informed consent to publish the clinical data. All protocols were followed according to institutional guidelines.

\section{References}

1. Lu H, Stratton CW, Tang YW. Outbreak of pneumonia of unknown etiology in Wuhan, China: The mystery and the miracle. J Med Virol. 2020;92(4):401-2.

2. Hoffmann M, Kleine-Weber H, Schroeder S, Krüger N, Herrler T, Erichsen S, et al. SARS-CoV-2 Cell Entry Depends on ACE2 and TMPRSS2 and Is Blocked by a Clinically Proven Protease Inhibitor. Cell. 2020;181(2):271-280.e8.

3. Suri JS, Puvvula A, Biswas M, Majhail M, Saba L, Faa G, et al. COVID-19 pathways for brain and heart injury in comorbidity patients: A role of medical imaging and artificial intelligence-based COVID severity classification: A review. Comput Biol Med. 2020;124:103960. Review.

4. Yokoo P, Fonseca EK, Sasdelli Neto R, Ishikawa WY, Silva MM, Yanata E, et al. COVID-19 myocarditis: a case report. einstein (Sao Paulo). 2020;18:eRC5876.

5. Hartmann C, Miggiolaro A, Motta Junior JS, Carstens LB, Paula CB. Grobe SF, et al. The Pathogenisis of COVID-19 Myocardial Injury: an Immunohistochemical Study of Postmortem Biopsies. 
6. Garg R. Spectrum of Neurological Manifestations in Covid-19: A Review. Neurol India. 2020;68(3):560-72. Review.

7. Esfandiarei M, McManus BM. Molecular biology and pathogenesis of viral myocarditis. Annu Rev Pathol. 2008;3(1):127-55. Review.

8. Felker GM, Boehmer JP, Hruban RH, Hutchins GM, Kasper EK, Baughman KL, et al. Echocardiographic findings in fulminant and acute myocarditis. J Am Coll Cardiol. 2000;36(1):227-32.

9. Huang C, Wang Y, Li X, Ren L, Zhao J, Hu Y, et al. Clinical features of patients infected with 2019 novel coronavirus in Wuhan, China. Lancet. 2020 Jan 30

10. Mehta P, McAuley DF, Brown M, Sanchez E, Tattersall RS, Manson JJ ; HLH Across Speciality Collaboration, UK. COVID-19: consider cytokine storm syndromes and immunosuppression. Lancet. 2020;395(10229):1033-4.

11. Musher DM, Rueda AM, Kaka AS, Mapara SM. The association between pneumococcal pneumonia and acute cardiac events. 2007;45(2):158-65.

12. Paul JF, Charles P, Richaud C, Caussin C, Diakov C. Myocarditis revealing COVID-19 infection in a young patient. Eur Heart J Cardiovasc. 2020;21(7):776. Review.

13. Inciardi RM, Lupi L, Zaccone G, Italia L, Raffo M, Tomasoni D, et al. Cardiac Involvement in a Patient with Coronavirus Disease 2019 (COVID-19). JAMA Cardiol. 2020;5(7):819-24.

14. Shi S, Qin M, Shen B, Cai Y, Liu T, Yang F, et al. Association of Cardiac Injury with Mortality in Hospitalized Patients with COVID-19 in Wuhan, China. JAMA Cardiol. 2020;5(7):802-10.

15. Zhang H, Baker A. Recombinant human ACE2: acing out angiotensin II in ARDS therapy. Crit Care. 2017;21(1):305.

\section{Figures}




\section{Cardiac Troponin I (pg/mL)}

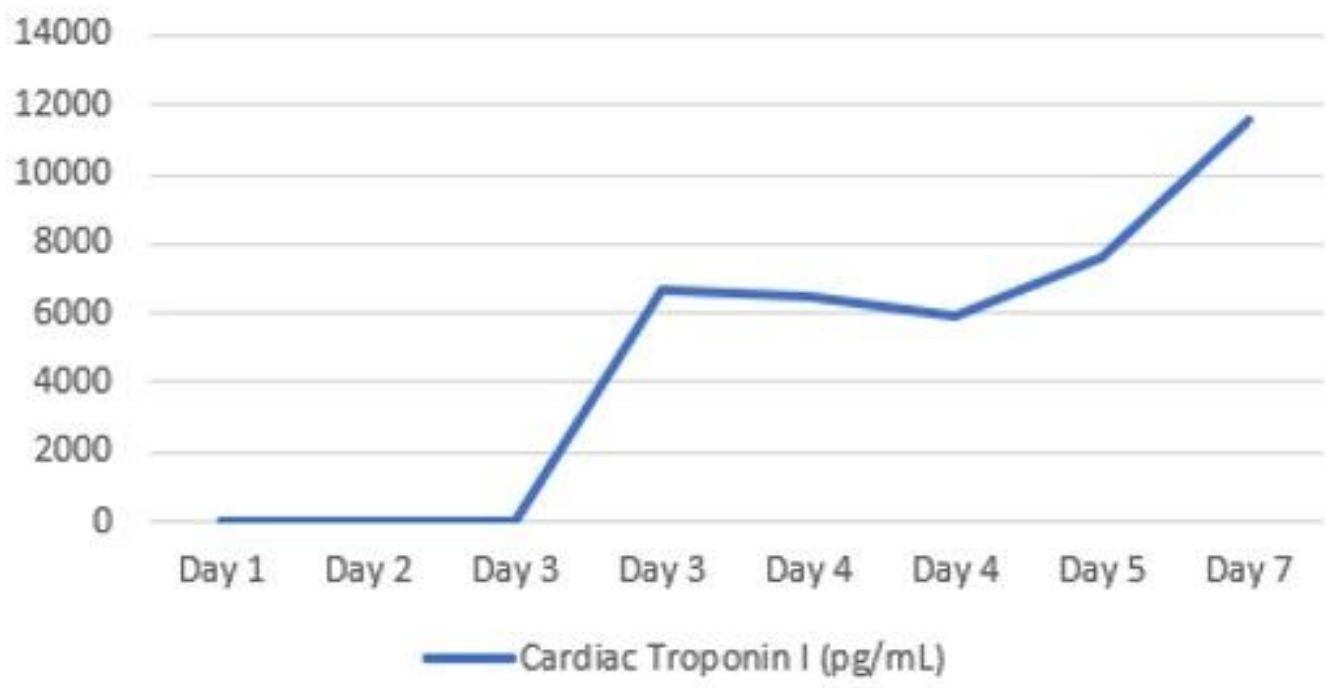

${ }^{*}$ Cardiac troponin I values were not obtained on the 6 th and 8 th day

\section{Figure 1}

Elevation of cardiac troponin throughout hospitalization

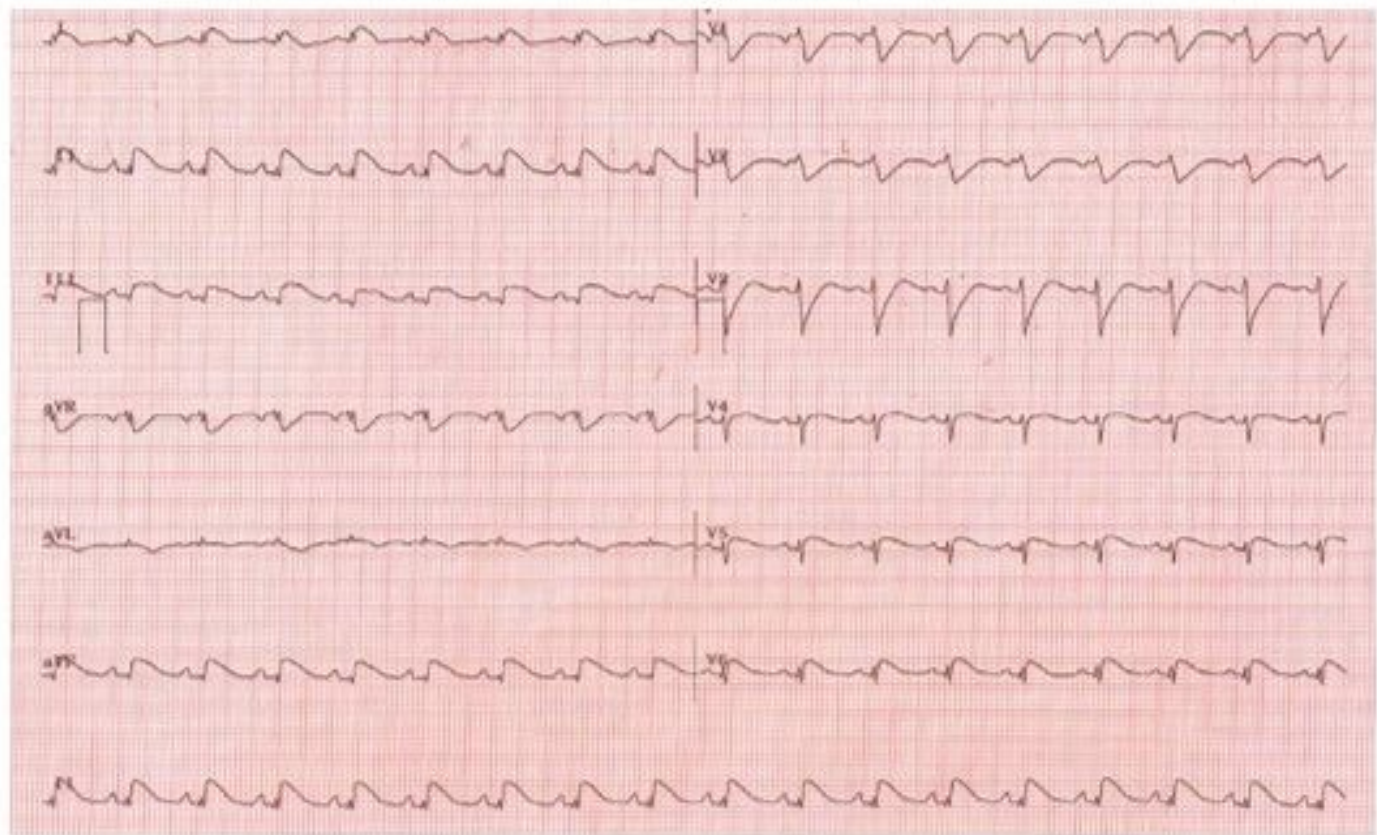

Figure 2

Electrocardiogram obtained on day 6 